\title{
Spermatogenesis of riffle bugs, Rhagovelia whitei and Rhagovelia sp (Veliidae), and backswimmers Martarega sp (Notonectidae)
}

\author{
M.M.U. Castanhole, L.L.V. Pereira, H.V. de Souza and M.M. Itoyama \\ Laboratório de Citogenética e Molecular de Insetos, \\ Departamento de Biologia, Instituto de Biociências, Letras e Ciências Exatas, \\ Universidade Estadual Paulista "Júlio de Mesquita Filho", \\ São José do Rio Preto, SP, Brasil \\ Correspondent author: M.M. Itoyama \\ E-mail: mary@ibilce.unesp.br
}

Genet. Mol. Res. 11 (3): 2003-2020 (2012)

Received August 10, 2011

Accepted October 20, 2011

Published August 6, 2012

DOI http://dx.doi.org/10.4238/2012.August.6.5

\begin{abstract}
We examined the course of spermatogenesis and the meiotic chromosome complements in aquatic species of true bugs, Heteroptera. The chromosome complement of the Veliidae species was $2 \mathrm{n}=39(38 \mathrm{~A}+\mathrm{X} 0)$ and $23(22 \mathrm{~A}+\mathrm{X} 0)$ in Rhagovelia whitei and Rhagovelia sp, respectively, and in the species of the Notonectidae (Martarega $\mathrm{sp})$ it was $26(22 \mathrm{~A}+2 \mathrm{~m}+\mathrm{XY})$; all collected from the region of São José do Rio Preto, SP, Brazil. An impressive characteristic of the first analysis was the size of the cells belonging to Martarega sp, which were six times larger than the same cells in Pentatomidae and twice as large as the cells in aquatic Heteroptera (Gerridae). Regarding spermatogenesis, all the species analyzed showed the same pattern: holocentric chromosomes and elongated spermatids with the chromatin distributed evenly along the head. The family Veliidae showed several bodies impregnated with silver nitrate at prophase, while the family Notonectidae displayed only one. The cells of Notonectidae also showed an evident and round
\end{abstract}


body until the end of prophase I and in the family Veliidae the silverimpregnated bodies were disorganized, where the only region visualized was possibly that of the NOR. In metaphase, silver-stained regions were found at the periphery of all chromosomes in Veliidae and at the periphery of some chromosomes in Notonectidae. The spermatids of Veliidae showed a less silver-impregnated vesicle, while Notonectidae showed silver staining only in part of the nuclear membrane. Therefore, families of Heteroptera have some differences and features that can help identify and classify these species.

Key word: Spermiogenesis; NOR; Aquatic heteropteran; Meiosis; Vesicle

\section{INTRODUCTION}

The insects from the family Notonectidae are commonly known as backswimmers, because they swim or set out at full tilt on their backs. Besides, they are characterized as possessing posterior legs adapted for swimming. The species of the family Veliidae are small, gregarious predators that live on the water surface, like the family Gerridae (Ueshima, 1979).

The number of autosomes in Heteroptera ranges from four (Belostomatidae) to 80 (Miridae), but these numbers are not typical in this suborder (Ueshima, 1979). According to Ueshima (1979), only 12 species and two genera belonging to the family Notonectidae have been cytogenetically analyzed. The genus Anisops (Anisopinae) is characterized by a sex chromosome system of $\mathrm{X}_{1} \mathrm{X}_{2} 0 / \mathrm{X}_{1} \mathrm{X}_{1} \mathrm{X}_{2} \mathrm{X}_{2}$ (male/female), presence of a pair of m-chromosomes and diploid number of chromosomes of 26 in males and 28 in females. Species of the genus Notonecta (Notonectidae) analyzed showed a male sex chromosome system of $\mathrm{X} 0$ or XY and chromosome complements of $2 \mathrm{n}=24(20 \mathrm{~A}+2 \mathrm{~m}+\mathrm{XY})$ or $26(22 \mathrm{~A}+2 \mathrm{~m}+$ $\mathrm{XY}$ ). Angus et al. (2004) showed that the karyotypes of other some male species of genera Notonecta were $2 \mathrm{n}=22 \mathrm{~A}+\mathrm{XY}$ and $24 \mathrm{~A}+\mathrm{XY}$.

In Veliidae, males of Hebrovelia sp and Microvelia reticulata have chromosome complements of $2 \mathrm{n}=21(20 \mathrm{~A}+\mathrm{X} 0)$ (Cobben, 1968), and Velia currens (Poisson, 1936) and Velia sp (Ueshima, 1979) show $2 \mathrm{n}=25(24 \mathrm{~A}+\mathrm{X} 0)$, M. reticulata $2 \mathrm{n}=20 \mathrm{~A}+\mathrm{X} 0$, and Velia (Plesiovelia) pelagonensis $2 \mathrm{n}=24 \mathrm{~A}+\mathrm{X} 0$ (Grozeva et al., 2009). In spite of all reports describing species that have a sex chromosome system of X0, Takenouchi and Muramoto (1971) suggested the XY system for Microvelia douglasi, but this needs to be confirmed (Ueshima, 1979).

Heteroptera, in general, show holocentric chromosomes (without localized centromere), which have a large kinetocore plate that cover most of the chromosome surface (Rufas and Giménez-Martín, 1986; Wolf, 1996); terminal chiasmata are supposed to occur (John and King, 1985), although there are studies questioning this point (Solari and Agopian, 1987), and the first meiotic division is reductional for the autosomes and equational for the sex chromosomes.

The sex chromosomes are achiasmatic and they behave as univalents in male meiosis. They separate equationally in anaphase I, forming a pseudobivalent in meiosis II. However, pre-reduction of the sex chromosomes was found in a few species of the family Tingidae 
(Ueshima, 1979; Grozeva and Nokkala, 2001). Finally, the m-chromosomes, small pair of chromosomes present in some families, are also achiasmatic, but they associate in the first division and segregate pre-reductionally (Papeschi et al., 2003).

A structure that has been poorly studied is the nucleolus. It is known that its size is related to biosynthetic cell activity, and therefore, the size and the number of nucleoli and pre-nucleolar bodies depend on the functional characteristics of the cells, and they can thus account for metabolic and functional differences (Tavares and Azeredo-Oliveira, 1997; Souza et al., 2007a). The persistence of the nucleolus and pre-nucleolar bodies observed through the meiosis of Dysdercus imitator (Pyrrhocoridae, Heteroptera) can then be related to the intense synthetic activity required to produce rRNA for spermatogenesis. However, there is the possibility that the high levels of rRNA transcription can be related to another factor (Bressa et al., 2003).

The number and the location of nucleolar organizing regions (NORs) are known in a few species of Heteroptera, having been determined with different cytogenetic techniques. All of the species described have shown a single NOR located in the middle or subterminal position of an autosome or of a sex chromosome (González-García et al., 1996; Papeschi and Bressa, 2002; Papeschi et al., 2003; Cattani and Papeschi, 2004; Castanhole et al., 2008). Recently, Bressa et al. (2009) reported two NORs in the X chromosome of Dysdercus albofasciatus, resulting from a gonosome-autosome fusion, one of the NORs originating from the ancestral X chromosome and the other from the autosome.

Considering the cytogenetic variations shown by the group, the objective of the present study was to analyze cytogenetically (spermatogenesis and nucleolar behavior) species of the families Veliidae and Notonectidae.

\section{MATERIAL AND METHODS}

Ten male samples of each of the species Rhagovelia whitei (Breddin) and Martarega sp were collected from the reservoir of the municipal dam of the city of São José do Rio Preto, São Paulo, Brazil, and ten species of Rhagovelia sp from the Piedade River, close to the city of São José do Rio Preto (20 $47^{\prime} 32^{\prime \prime}$ S, $\left.49^{\circ} 21^{\prime} 37^{\prime \prime} \mathrm{W}\right)$, with traps and transported in pots to the Laboratory of Cytogenetics and Molecular Genetics of Insects (LACIMI).

The species were separated by sex, fixed in methanol:acetic acid (3:1), and kept in a refrigerator until the preparation of slides with the squash technique using either lacto-acetic orcein dye or impregnation with silver nitrate (Howell and Black, 1980). The slides were analyzed with a Zeiss AXIOSKOP 2 microscope with a 12-V/100-W light bulb, and images were captured with the built-in Digital Image Processing AXIONVISION 3.1 (Zeiss) software.

\section{RESULTS}

The species of the family Veliidae possess testes formed by only one rounded testicular lobe covered by a transparent peritoneal sheath. On the other hand, the species of the family Notonectidae have testes formed by two lobes, with a spiral shape and also surrounded by a transparent peritoneal sheath.

During dissection, a large amount of fatty tissue was observed in the abdominal cavity, among the organs. 


\section{Spermatogenesis of the Veliidae family}

The analysis of the testes of $R$. whitei and Rhagovelia sp (Veliidae) showed that cells in prophase I (leptotene-pachytene) (Figure 1a,b) possess a single round and evident heteropyknotic body. In both species, bivalents with interstitial chiasmata (Figures 1c,d and 2a) were observed from the end to prophase I (Figure 1d). At the end of prophase I, the chromosomes of $R$. whitei associate by forming groups with different amounts of chromosomes (Figure 2b). The analysis of metaphase I showed that $R$. whitei possesses $\mathrm{n}$ $=20(19+\mathrm{X} 0)$ chromosomes and Rhagovelia sp possesses $\mathrm{n}=12(11+\mathrm{X} 0)$ chromosomes (Figure $2 \mathrm{c}-\mathrm{g}$ ). The cells in telophase are proportionally of the same size as those of the other phases in meiosis (Figure $3 a$ ).
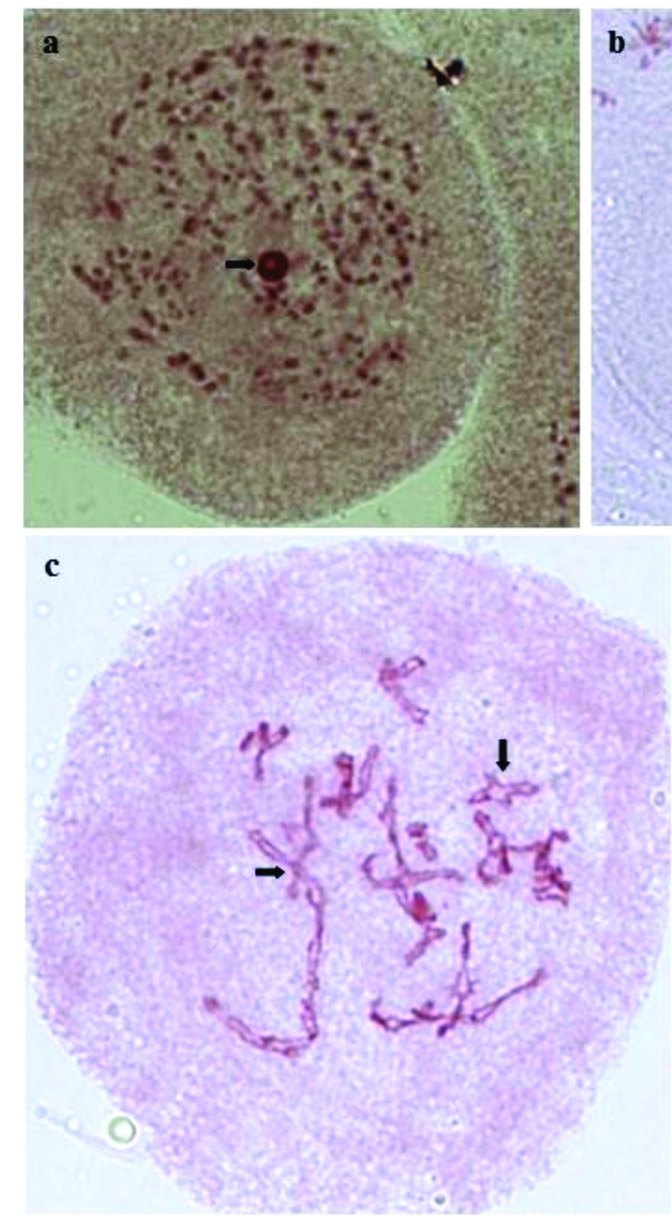

Figure 1. Testicular cells of adult males of Rhagovelia whitei (b, c) and Rhagovelia sp (a, d) stained with lactoacetic orcein. a. Prophases I in early development (leptotene), with a heteropyknotic body (arrow). b. Pachytene with heteropyknotic body (arrow). c. Cell in diplotene, with the presence of interstitial chiasmata (arrows). d. Diakinesis: note the presence of interstitial chiasmata (arrows). Bar $=10 \mu \mathrm{m}$. 

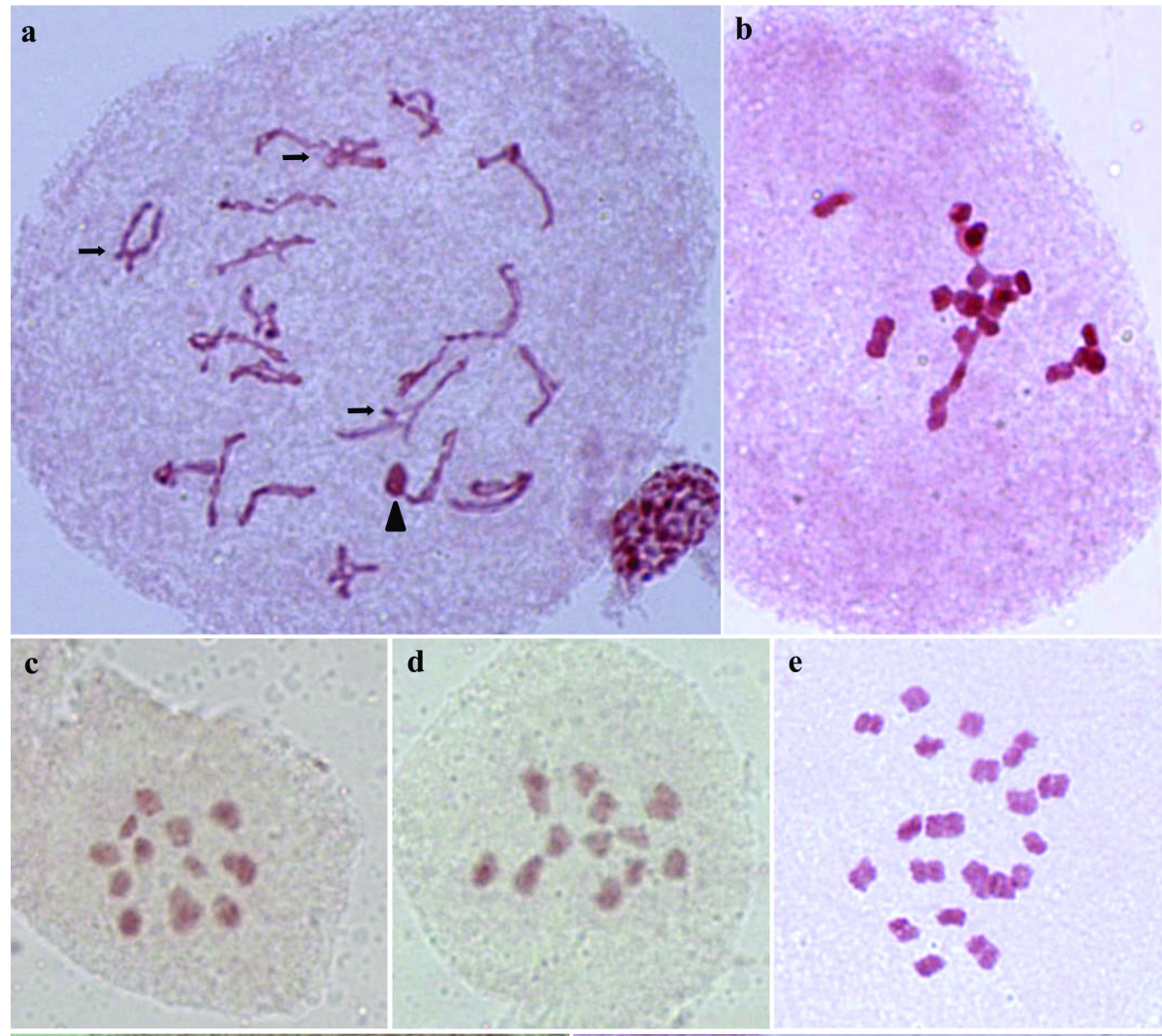

e
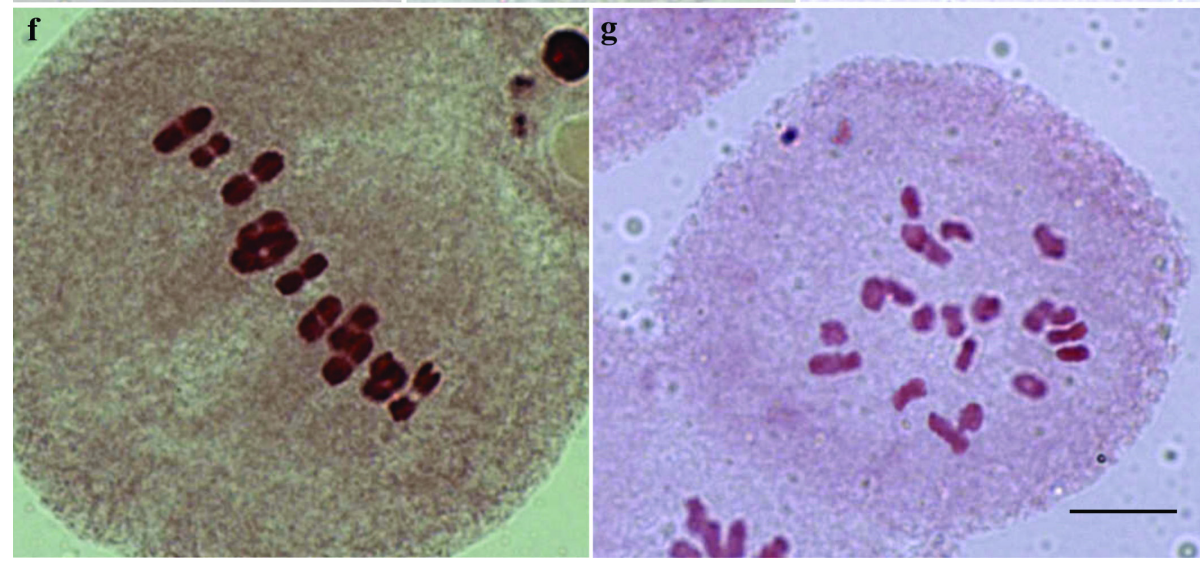

Figure 2. Testicular cells of adult males of Rhagovelia whitei (a, b, e, g) and Rhagovelia sp (c, d, f) stained with lacto-acetic orcein. a. Cell in diplotene/diakinesis: note the presence of interstitial chiasmata in most of the autosomes (arrows) and the association of the X chromosome with a bivalent (arrowhead). b. Note that at the end of prophase the chromosomes associate forming two groups, where one is larger than the other, and isolated chromosomes are still observable. c.-e. Metaphases in polar view showing $\mathrm{n}=12$ chromosomes $(11+\mathrm{X} 0$; c,d $)$ and $\mathrm{n}=20$ chromosomes $(19+\mathrm{X} 0$; e). f. Metaphase I in lateral view, clearly showing 11 autosome bivalents and an $\mathrm{X}$-chromosome. g. Metaphase I in polar view. Bar $=10 \mu \mathrm{m}$. 


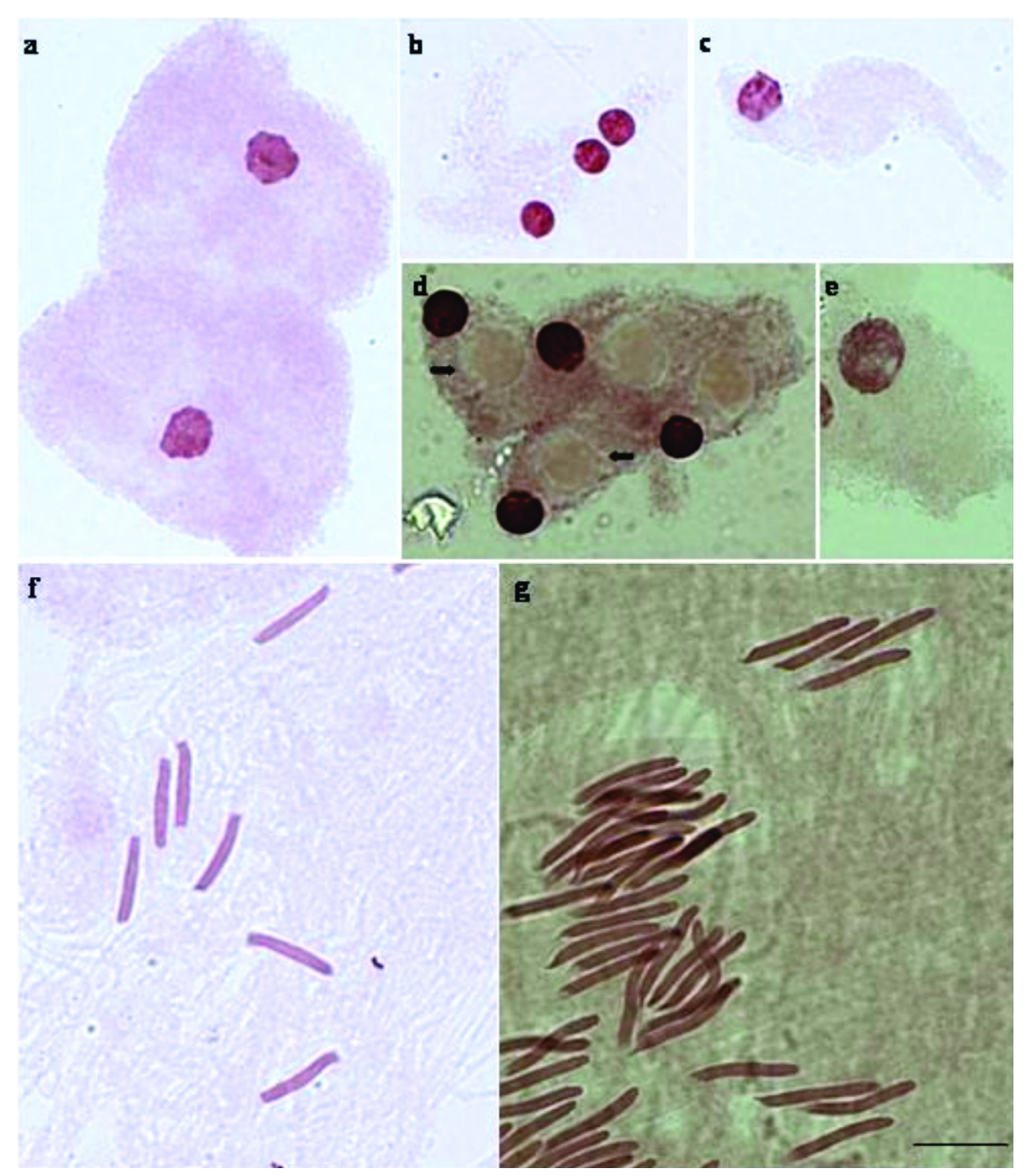

Figure 3. Testicular cells of adult males of Rhagovelia whitei (a, b, c, f) and Rhagovelia sp (d, e, g) stained with lacto-acetic orcein. a. Telophase. b.c. Spermatids with round chromatin material. d. Spermatids with the presence of a large vesicle (arrows). e. Elongating nuclei of spermatids. f.g. Spermatids with rod-shaped head, intensely stained with orcein. Bar $=10 \mu \mathrm{m}$.

The spermatids of $R$. whitei are round and possess some heteropyknotic bodies (Figure $3 \mathrm{~b}, \mathrm{c})$ and Rhagovelia sp possess, besides the heteropyknotic bodies, a large and round vesicle close to the nucleus (Figure 3d), which later disappears (Figure 3e). During elongation, the spermatids are rod-shaped, with the chromatin distributed along the head (Figure 3f,g).

\section{Spermatogenesis of the Notonectidae family}

The analysis of the testes of Martarega sp (Notonectidae) showed a cell in early pro- 
phase I (leptotene/zygotene) with a round heteropyknotic region of variable morphology (Figure 4a). Another observation made in this species is in regard to the size of the meiotic cells. For evidence, we show cells of other species in the same phase of development and at the same magnification. In $4 \mathrm{~b}$, there are cells of Thyanta perditor (Pentatomidae), and in $4 \mathrm{c}$ cells of Halobatopsis platensis (Gerridae), which are respectively 6x and 2x smaller in diameter than the cells of Martarega sp.

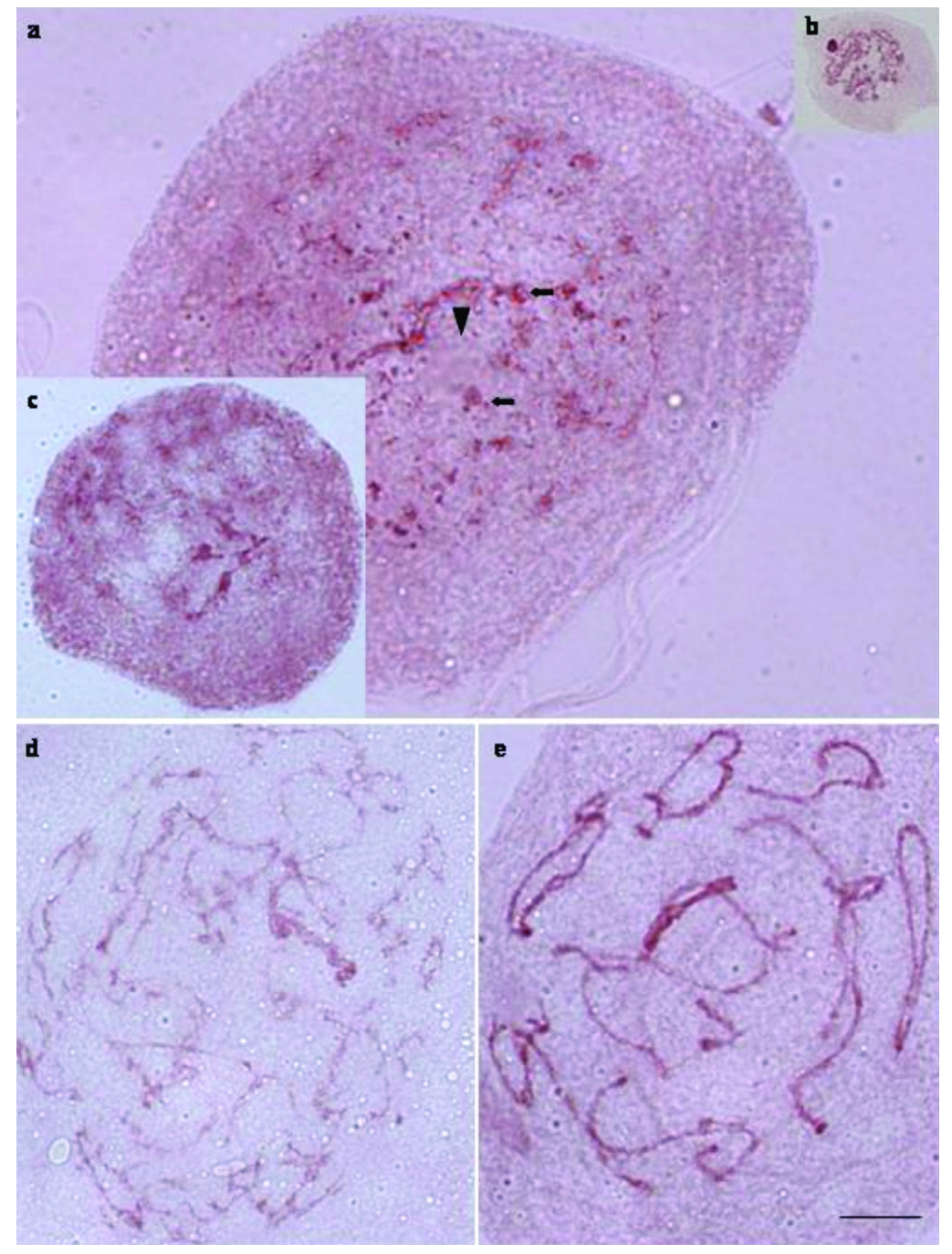

Figure 4. Testicular cells of adult males of Martarega sp stained with lacto-acetic orcein. a. Prophases beginning the process of condensation of the chromosomes, with the presence of a heteropyknotic body (arrows). Note, still, the presence of the nucleolus (arrowhead). b.c. Note highlighted cells of Thianta perditor (Pentatomidae) and of Halobatopsis platensis (Gerridae), respectively; these cells show very different sizes, considering that they are at the same magnification. d.e. Cells in prophase (pachytene). Note the size and the condensation of the chromosomes. Bar $=10 \mu \mathrm{m}$. 
During every meiotic process, the cells are similar in size. The chromosomes were condensed (Figure $4 \mathrm{c}$ and $\mathrm{d}$ ), and the presence of chiasmata could be observed (Figure 4d). At the end of prophase I, the autosome chromosomes are seen to be associated in the telomeric region, and there are few chromosomes with chiasmata (Figure 5a). In metaphase I, the autosomal bivalents form a ring apparent in polar view. Two small chromosomes and two unequal medium-sized chromosomes (probably the $\mathrm{X}$ and $\mathrm{Y}$ ) lie in the center of the ring. The chromosome complement is $\mathrm{n}=15(11+2 \mathrm{~m}$ $+\mathrm{XY}$ ) (Figure $5 \mathrm{~b}$ and c). The chromosomes usually separate in anaphase, and they unite during the telophase with two cells of similar size, and each one similar in size to the other cells in the preceding phases (Figure 5d). At the end of telophase, a telomeric association is observed among almost all of the chromosomes, forming a ring. In the center of the ring, there is a very small group of chromosomes, and outside the ring there is a group of heteropyknotic chromosomes, which are possibly the sex chromosomes, associated with one of the chromosomes of the ring (Figure 6a).
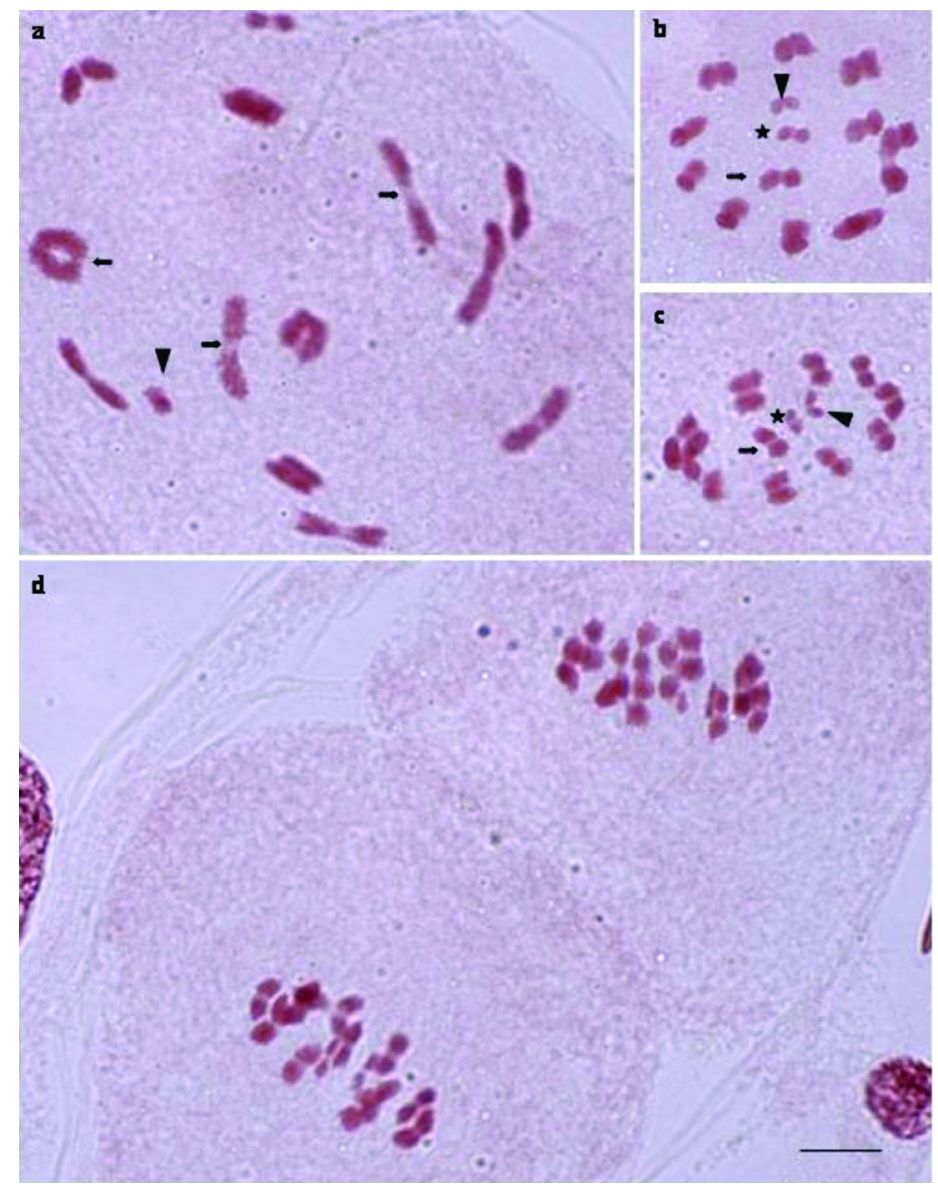

Figure 5. Testicular cells of adult males of Martarega sp stained with lacto-acetic orcein. a. Cell in diplotene/ diakinesis, showing the telomeric association among the chromosomes (arrows). Note also the m-chromosomes (arrowhead). b.c. Metaphases I, in polar view, with the autosomes forming a ring with the sex chromosomes XY (X, arrows; $\mathrm{Y}$, asterisks), and the $\mathrm{m}$-chromosomes (arrowheads) in the center. Chromosome complement of Martarega $\mathrm{sp}$ is $\mathrm{n}=15(11+2 \mathrm{~m}+\mathrm{XY})$. d. Cell in telophase, note the size of the cells in formation. Bar $=10 \mu \mathrm{m}$. 


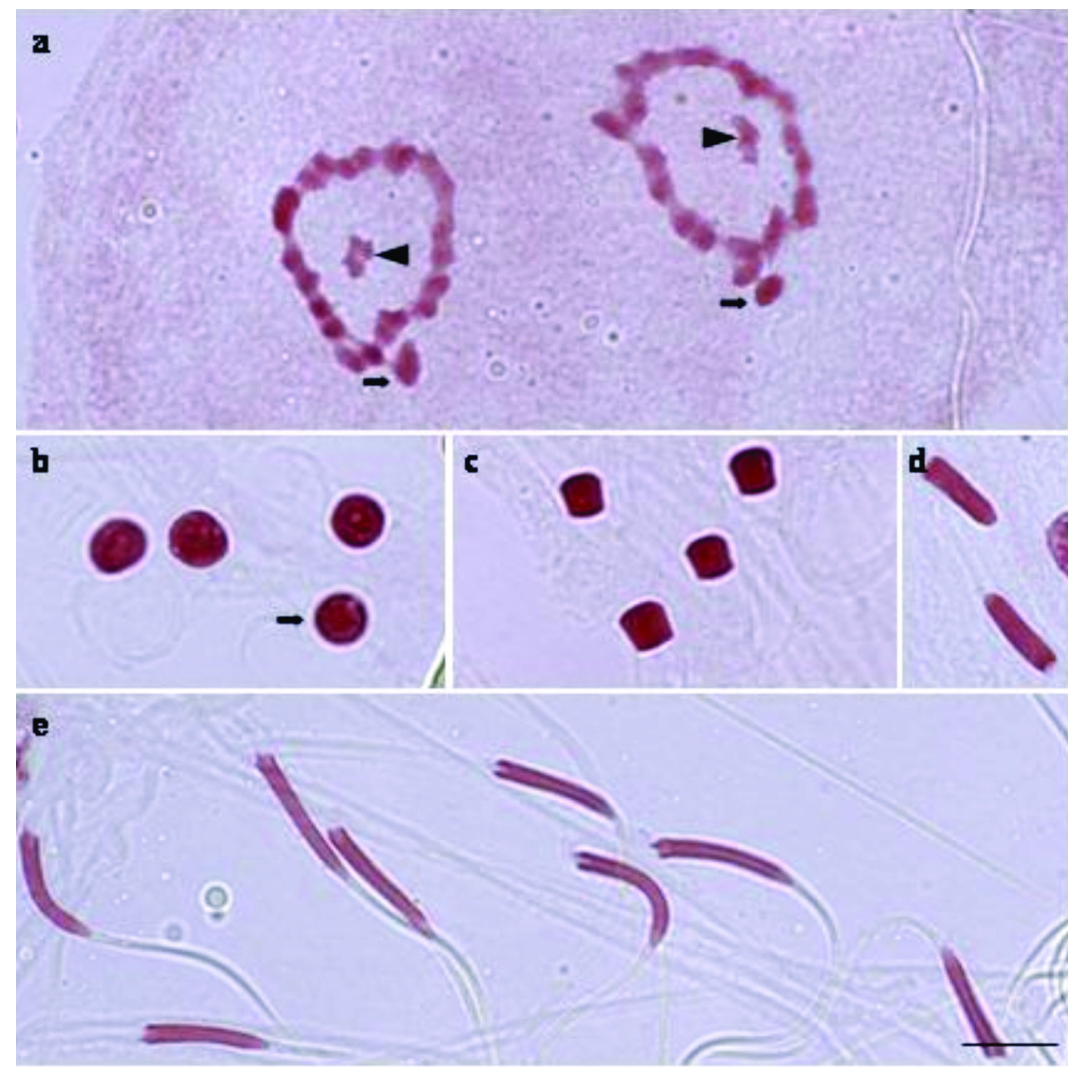

Figure 6. Testicular cells of adult males of Martarega sp stained with lacto-acetic orcein. a. Cell in telophase with the autosomes associated with the telomeric regions forming a circle with chromatin inside, possibly the m-chromosomes (arrowheads), linked to the circle, and located in the circle there is heteropyknotic material that possibly represents the sex chromosomes (arrows). b. Round spermatid with chromatin distributed evenly. c. Spermatid in beginning elongation, changing from round to square. d. Later, they take on a rod shape with chromatin material evenly distributed. $\mathbf{e}$. Note the head and tail region of the spermatid in formation. Bar $=10 \mu \mathrm{m}$.

The recently formed spermatids are round and have an inner region that is also round and not stained with orcein (Figure $6 \mathrm{~b}$ ). During elongation, the spermatids acquire a square shape (Figure 6c), and with development they become elongated in acquiring a rod shape with the chromatin distributed evenly in the head (Figure 6d and e).

\section{Nucleolar behavior of the Veliidae family}

The prophase I (zygotene-pachytene) of $R$. whitei and Rhagovelia sp impregnated with silver nitrate showed two bodies that begin disorganizing, only remaining in some regions of the chromosomes, but without defined morphology (Figure 7a-c). At the end of prophase I (diplotene) in Rhagovelia sp, silver staining can be seen in the telomeric region of one of the autosomes. The association of this chromosome occurs in the telomeric regions, as already defined for Heteroptera, but we can see that this association does not involve the end that possesses the NOR. These 
regions do not participate in the association (Figure 7c). In Rhagovelia sp, silver staining of NORs was not observed in any of the autosomes. In the metaphase of this species, there were three autosomes observed with evident silver staining at the periphery of the chromosome (Figure 7d). Silver staining in $R$. whitei was also found at the periphery of the chromosome, involving a larger number of autosomes, but fewer impregnated ones (Figure 7e). At metaphase of Rhagovelia sp the telomeric association of chromosomes could be observed (Figure 7f). At the end of telophase, one of the cells recently formed by $R$. whitei shows silver staining (Figure 8a), while this is not seen in Rhagovelia sp (Figure $8 b$ ). The spermiogenesis process begins with round spermatids with $(R$. whitei) or without (Rhagovelia $\mathrm{sp}$ ) silver-impregnated material. The silver-impregnated material of $R$. whitei appears round and intense and it is located close to the chromatin (Figure 8ce). With elongation, there is a decrease in silver staining and these stained regions are distributed evenly throughout the whole spermatid (Figure $8 \mathrm{f}$ and $\mathrm{g}$ ). At the end of the process, the spermatids of $R$. whitei possess intense silver staining in the anterior region of the head (Figure $8 \mathrm{~h}$ ).

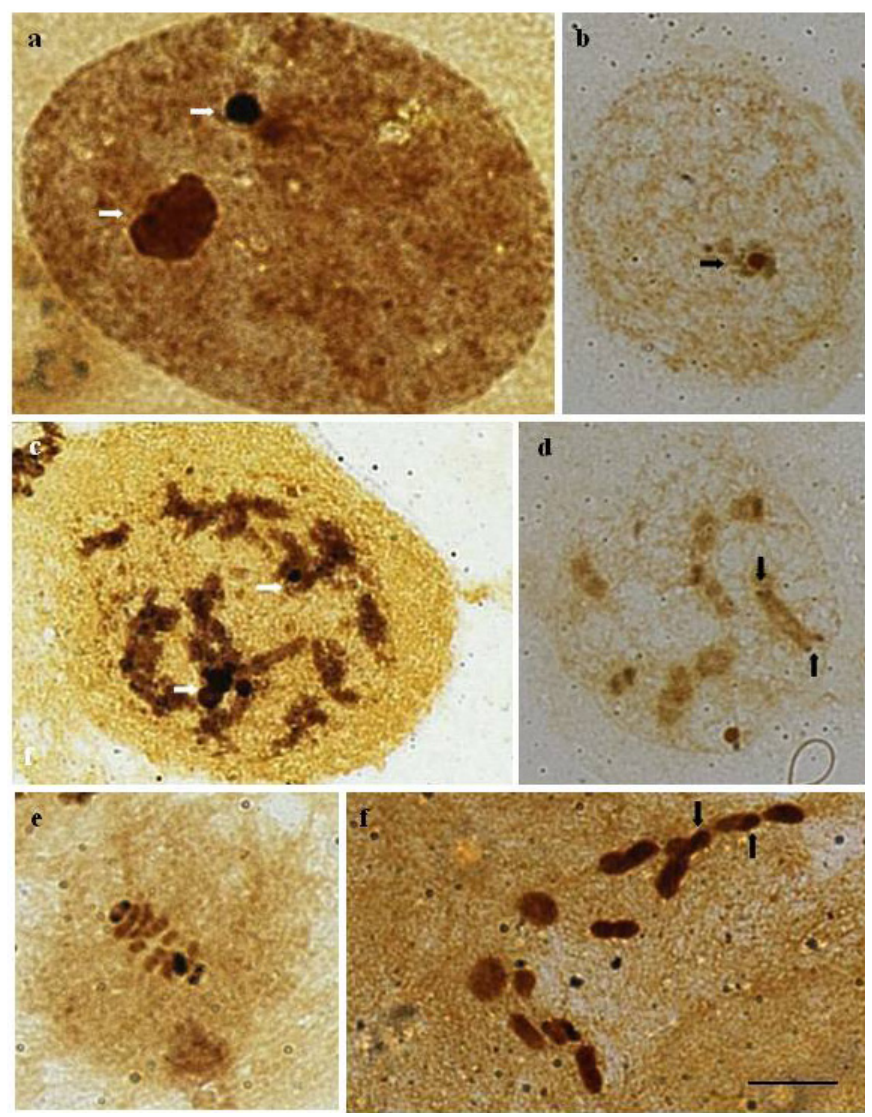

Figure 7. Testicular cells of adult males of Rhagovelia whitei (a, c, e) and Rhagovelia sp (b, d, f) impregnated with silver nitrate. a. Early prophase (leptotene), with two bodies, with one larger than the other (arrows). b. Initial prophase with one corpuscle (arrow). c. Note that the bodies already disorganized could be observed in this material only in some chromosomes (arrows). d. Diplotene/diakinesis showing a chromosome with a marking of NOR in the telomeric regions (arrows). e.f. Metaphases showing the presence of silver staining at the periphery of the chromosome, being more evident in Rhagovelia sp (f, arrows). Note in Rhagovelia sp the telomeric association of the chromosomes. Bar $=10 \mu \mathrm{m}$. 


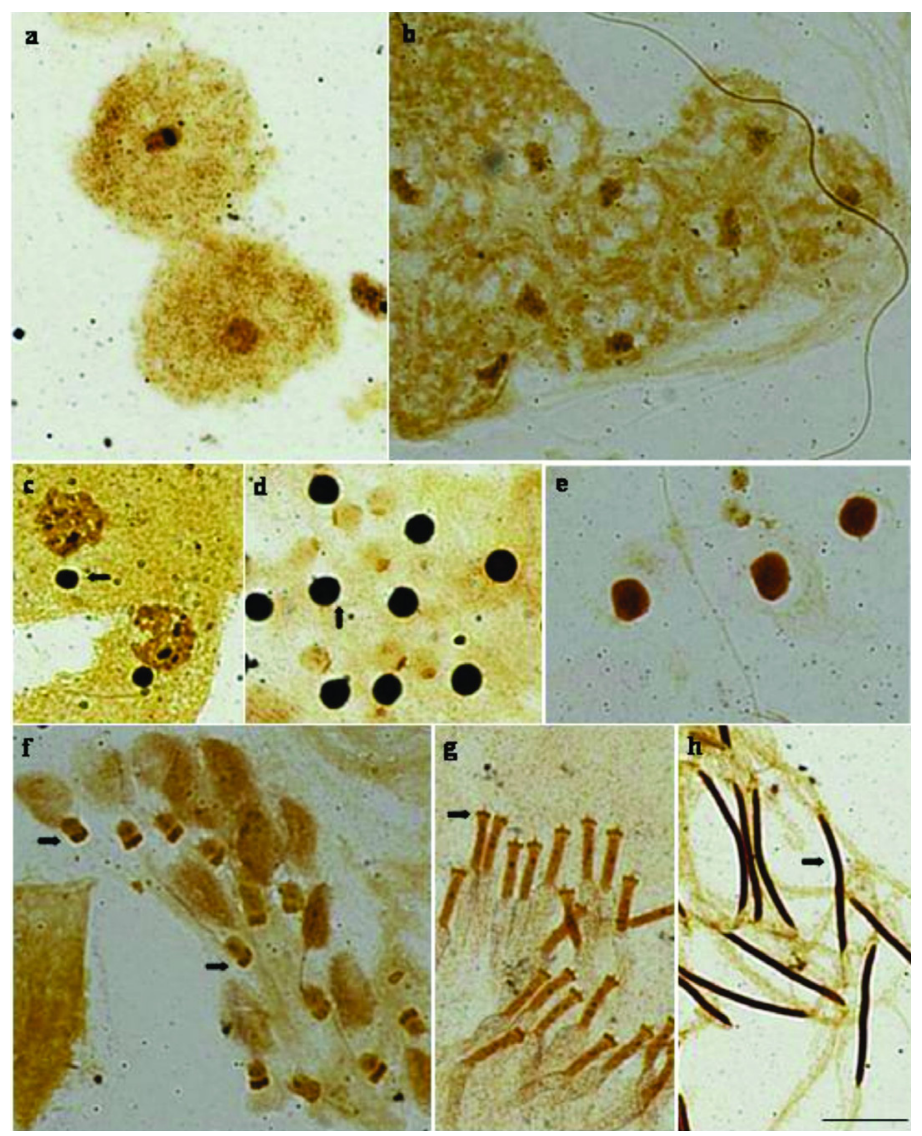

Figure 8. Testicular cells of adult males of Rhagovelia whitei (a, c, d, g, h) and Rhagovelia sp (b, e, f) impregnated with silver nitrate. a. Telophase with impregnation in only one of the cells recently formed. b. Cells without impregnation. c.d. Round spermatids with silver-positive impregnation close to the chromatin material (arrows). e. Spermatids without the marking by silver-staining. f.g. Spermatids being elongated, showing greater silver staining in the anterior area of the head (arrows). h. Elongated spermatids with intense marking by silver staining (arrow). Bar $=10 \mu \mathrm{m}$.

\section{Nucleolar behavior of the Notonectidae family}

The beginning of prophase I (leptotene) of Martarega sp showed two round bodies, one of them larger than the other (Figure 9a). Although the process of chromatin condensation is in progress, two bodies are still observable; there is a reduction in size, and one of them is around seven times larger with fewer impregnated regions than the other (Figure 9b). At leptotene/pachytene, the reduction of the bodies continues, but the two bodies can still be observed (Figure 9c). At diplotene, a single large body intensely impregnated was observed (Figure 9d). At metaphase I, two bodies in different bivalents were observed, possibly due to the NOR located in the telomeric region. It is also possible to observe, in one of the bivalents, that the association between the homologues does not involve the supposed NOR. In both bivalents, just one NOR of one homologue was active. At metaphase I, there were still autosomes with silver 
staining at the periphery of the chromosome (Figure 10a). In the beginning of spermiogenesis, the round spermatids showed silver staining in some regions of the nuclear peritoneal sheath (Figure 10b). With elongation, there was impregnation in two different regions of the spermatid, one large site in the anterior region and other much smaller in the posterior region (Figure 10c). In Figure 10d, the nucleus was homogeneously silver stained.

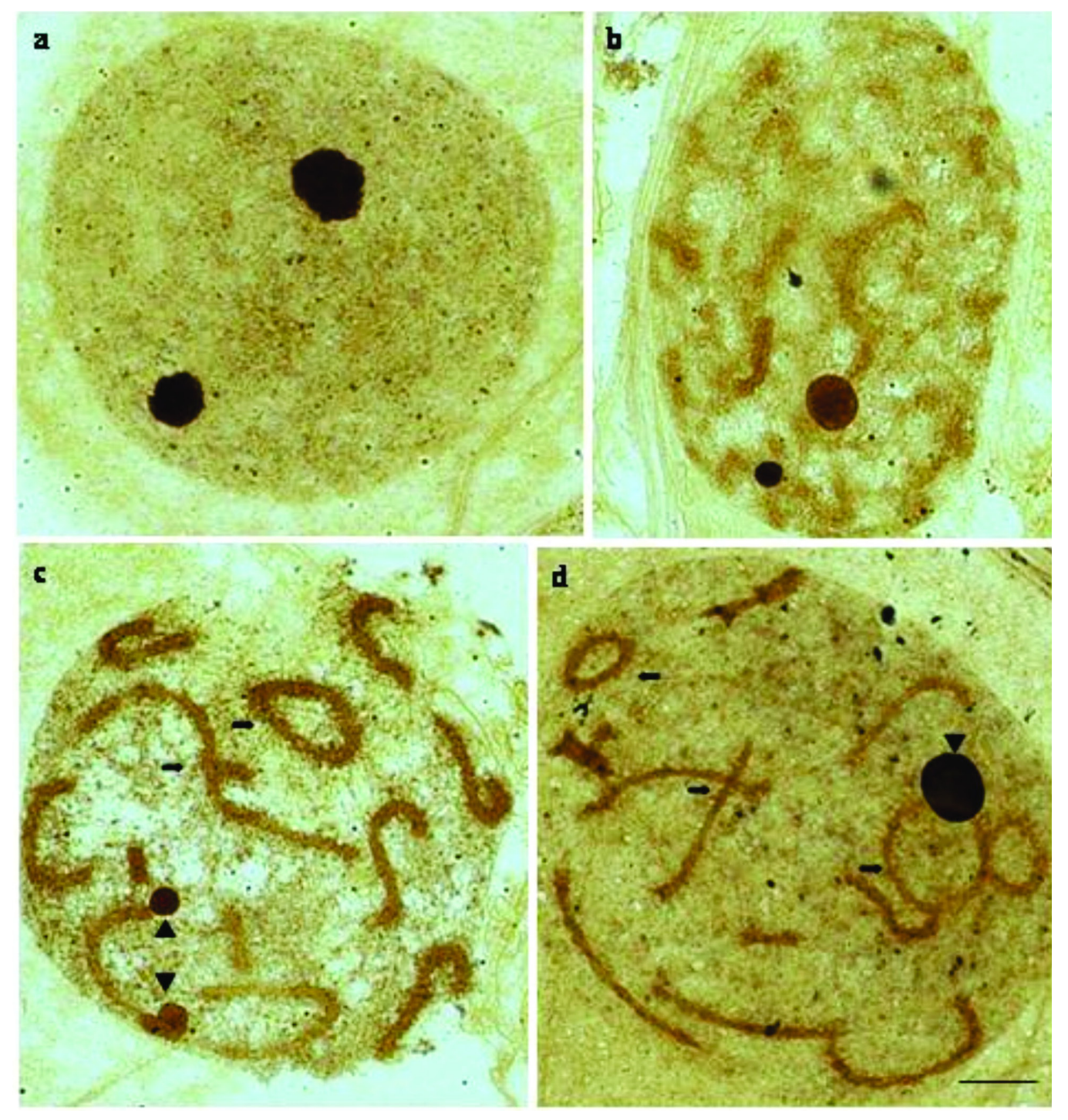

Figure 9. Testicular cells of adult males of Martarega sp impregnated with silver nitrate. a. Early prophase, showing two bodies, with one larger than the other. b. Early prophase (zygotene), beginning the condensation of the chromosomes and showing the two bodies, with one larger than the other and impregnated differently. c.d. Pachytenes/diplotenes showing interstitial and terminal chiasmata (arrows) and one (d) and two (c) large nucleolar bodies (arrowheads). Bar $=10 \mu \mathrm{m}$. 




Figure 10. Testicular cells of adult males of Martarega sp impregnated with silver nitrate. a. Metaphase I showing possible marking for NOR in two autosomes (arrows) and at the periphery of the chromosome in other autosomes (arrowheads). b. Round spermatids, with impregnation in the area of the nuclear envelope (arrow). c. Rod-shaped spermatid, with two demarcations by silver staining, one in the anterior part and the other in the posterior of the head (arrows). d. Elongated spermatid evenly silver impregnated (arrow). Bar $=10 \mu \mathrm{m}$.

\section{DISCUSSION}

The testes of Heteroptera are formed by variable numbers of lobes and covered by a peritoneal sheath of different coloration. Species of the Coreidae analyzed by Souza et al. 
(2007b) showed seven lobes covered by a red peritoneal sheath. Antiteuchus tripterus (Pentatomidae) also possesses testes covered by a red peritoneal sheath, but it is made up of six elongated lobes, where the sixth is inside the fifth (Souza et al., 2007c); Mormidae quinqueluteum, Oebalus poecilus and O. ypsilongriseus (Pentatomidae) also have a red peritoneal sheath covering the testes, but the number of elongated lobes found was 3, 4 and 4, respectively (Souza et al., 2008); Nysius californicus (Lygaeidae) has seven elongated lobes of similar size and covered by a red peritoneal sheath (Souza et al., 2007a), and Limnogonus aduncus (Gerridae) possesses two elongated lobes covered by a transparent peritoneal sheath (Castanhole et al., 2008). The species of the family Veliidae ( $R$. whitei and Rhagovelia $\mathrm{sp}$ ) analyzed in the present study showed a single round testicular lobe, and the species of the family Notonectidae (Martarega $\mathrm{sp}$ ) displayed spiraled testes formed by two lobes. Both families showed the testes covered by a transparent peritoneal sheath, differing from the other terrestrial families of Heteroptera, regarding the shape and peritoneal sheath that covers them. In spite of these differences, there are no studies in the literature that confirm a specific relationship with some family.

Another characteristic found in these organisms was the presence of great amount of fatty tissue in the thorax, as was observed in the belostomatid genus of Lethocerus, certain triatomine bugs such as Rhodnius prolixus and Triatoma infestans, the coreid Holopterna alata, the Nepidae (Nepa cinera), Naucoridae (Ilyocoris cimicoides), and Notonectidae (Notonecta glauca) families (Gäde et al., 2004, 2006, 2007a,b; Lorenz et al., 2009). It is believed that this characteristic is related to the great energy expenditure that these species need for survival in aquatic environments. Besides, it was observed that the testicular meiotic cells of terrestrial species are much smaller than those of aquatic ones, and when comparing the aquatic species studied nowadays, such cells of the families Gerridae (Castanhole et al., 2008, 2010) and Veliidae are smaller than those of the family Notonectidae. According to Gäde et al. (2004), N. glauca (Notonectidae) is very active and constantly swims around in captivity. When these bugs were subjected to $2 \mathrm{~h}$ of enforced rest, the hemolymph carbohydrates remained at constant levels but the lipid titers were much lower compared with those in swimming bugs, demonstrating that swimming is highly energy demanding.

We suggested that there are important data corroborating the habitat as an important factor, for example, for the definition of cell size, because individuals of the families Gerridae and Veliidae live on the surface of the waters, while those of the family Notonectidae are underwater species, and therefore, this last one needs a larger amount of energy to survive and swim.

Regarding the sex chromosome system and the chromosome complement of the species of Veliidae analyzed in the present study, they showed the same system (X0), but they differed regarding the chromosome complement ( 23 for Rhagovelia sp and 39 chromosomes for $R$. whitei). Although few cytogenetic studies on Veliidae species have been described, in all of them the sex chromosome system was $\mathrm{X} 0$, but they differed regarding the chromosome complement: Hebrovelia sp and M. reticulata, $2 \mathrm{n}=21(20 \mathrm{~A}+\mathrm{X} 0)$, V. currens and Velia $\mathrm{sp} 2 \mathrm{n}$ $=25(24 \mathrm{~A}+\mathrm{X} 0)($ Cobben, 1968; Ueshima, 1979). Although the few species described in the literature and analyzed in the present study show the same sex chromosome system of X0, Takenouchi and Muramoto (1971) observed the XY system for M. douglasi. However, according to Ueshima (1979) and also our findings, further analysis of this species is needed to confirm the sex chromosome system in this family.

The species of the family Notonectidae that are described in the literature show mchromosomes, but they differ regarding the sex chromosome system $\left(\mathrm{X}_{1} \mathrm{X}_{2}\right.$, Anisops; $\mathrm{XY}$, 
Notonecta) and the chromosome complement of 24 or 26 chromosomes (Ueshima, 1979). The species Martarega sp analyzed in the present study also showed m-chromosomes and 26 $(2 \mathrm{n}=22 \mathrm{~A}+2 \mathrm{~m}+\mathrm{XY})$ chromosomes. As with the family Veliidae, this also needs to be more thoroughly studied to help understand the standard sex chromosome system of the family.

Other characteristics of spermatogenesis, such as the presence of holocentric chromosomes, interstitial and terminal chiasmas, a single heteropyknotic body in meiotic cells, telomeric association of the chromosomes, reductional meiosis for the autosomes and equational for the sex chromosomes, and ring configuration of the autosomes in metaphases, are standard in all Heteroptera analyzed, regardless of the family, habitat or habit (Souza et al., 2007a,b,c, 2008; Bardella et al., 2008). Maybe one of the only differences found during spermatogenesis is during spermiogenesis. The morphology of the spermatids is quite different when comparing the terrestrial and the aquatic insects, mainly in the elongation phase. The terrestrials show spermatids, in elongation, in the ellipse form, denominated as such due to their geometric shape, while all the aquatic species show a rod shape, and some possess a large vesicle, supporting that they have a larger reserve of metabolic synthetic products compared to other terrestrial Heteroptera.

Another characteristic, already mentioned, is regarding the synthetic activity of the cells of Veliidae, and this can be confirmed by the size and coloration of the structures impregnated with silver nitrate and nucleoli that remain during prophase I. Also, compared to the cells of the family Notonectidae, those of the Vellidae are larger. Therefore, this can actually be related to the habitat where they live, as it is known that the size of this structure is related to the biosynthetic activity of the cell. Therefore, the size and the number of nucleoli and pre-nucleolar bodies depend on the functional characteristics of the cells, and they can then account for metabolic and functional differences (Tavares and Azeredo-Oliveira, 1997). However, these are relationships that still need to be better studied.

Regarding nucleolar behavior during meiosis, the species of Heteroptera show behavior similar to that of the processes described in plants, in other words, a group of proteins remains associated with NORs. Another group is located at the periphery of the chromosomes, where it remains from late prophase to early telophase, and a third group of proteins and also RNAs are evenly distributed in the cytoplasm between prophase and telophase (Ochs et al., 1985; Fakan and Hernandez-Verdun, 1986; Fischer et al., 1991; Wachtler and Stahl, 1993; Schwarzacher and Wachtler, 1993; González-García et al., 1995; Dundr et al., 1997).

The proteins that are located in the NOR were described in Belostomatidae in the telomeric region of the sex chromosomes $\mathrm{X}$ and $\mathrm{Y}$ (Belostoma oxyurum and B. micantulum) or in the telomeric region of an autosome (Belostoma elegans) (Papeschi and Bressa, 2002). In Coreidae, a single NOR is present in the interstitial region of the largest autosome of Pachylis argentinus (Papeschi et al., 2003) or in the telomeric region of an autosome in Carlisi wahlbergi (Fossey and Liebenberg, 1995) and Spartocera fusca (Cattani and Papeschi, 2004). In Pentatomidae and Gerridae, a single NOR was detected in the telomeric region of an autosome in Edessa meditabunda and L. aduncus, respectively (Rebagliati et al., 2003; Castanhole et al., 2008), in the middle position of the largest autosome in Nezara viridula (Papeschi et al., 2003) or in the telomeric region of chromosome Y in Graphosoma italicum (González-García et al., 1996).

Another class of proteins was found at the periphery of the chromosome in metaphasic and anaphasic chromosomes in A. tripterus (Heteroptera, Pentatomidae) and N. californicus (Lygaeidae) (Souza et al., 2007a,c). In Triatoma brasiliensis and T. sordida (Heteroptera, Reduviidae), bodies stained with silver nitrate were observable up to metaphase I (Tavares and 
Azeredo-Oliveira, 1997). In C. wahlbergi (Heteroptera, Coreidae), nucleolar bodies were observed up to metaphase II (Fossey and Liebenberg, 1995), while in Acanthocoris sordidus (Heteroptera, Coreidae) and Coptosoma punctissimum (Heteroptera, Plataspidae) the nucleoli were detected in the metaphase plates of primary and secondary spermatocytes (Yoshida, 1947).

Rhagovelia sp and Martarega sp showed the presence of one or two NORs in the telomeric regions of the autosomes and at the periphery of the chromosome, respectively. In Rhagovelia sp, unlike what we observed in other insects (L. aduncus, Castanhole et al., 2008; E. meditabunda, Rebagliati et al., 2003), they had the NOR on the opposite side of the telomeric regions of the autosomes.

The silver-staining process also varies during spermiogenesis. According to Tartarotti and Azeredo-Oliveira (1999), in species of Panstrongylus (Heteroptera) silver staining was only visualized in the initial spermatid (round) and disappeared during elongation, corroborating the hypothesis of post-meiotic reactivation of rRNA genes. This process has also been observed in mammals and other vertebrates (Hofgärtner et al., 1979; Sumner, 1990). The number and the location of the silver-positive bodies also vary among the species of Heteroptera (Souza et al., 2007a,c, 2008). The species of Veliidae and Notonectidae also showed different behaviors. As can be seen, most of the characteristics are common for all species of Heteroptera, needing larger cytogenetic and molecular studies for more conclusive results, because the silver-staining technique is not specific enough to reveal nucleolar structures, as it is also used for the visualization of mitochondria, Golgi complex, and other structures.

\section{ACKNOWLEDGMENTS}

We thank Dr. Sonia Maria Oliani, from the Biology Department of IBILCE/UNESP, for the opportunity of capturing the cell images and Dr. Luiz Antônio Alves da Costa, from the National Museum of Rio de Janeiro, for the identification of the insects. Research supported by FAPESP, CAPES, and FUNDUNESP.

\section{REFERENCES}

Angus RB, Kemeny CK and Wood EL (2004). The C-banded karyotypes of the four British species of Notonecta L. (Heteroptera: Notonectidae). Hereditas 140: 134-138.

Bardella VB, Azeredo-Oliveira MT and Tartarotti E (2008). Cytogenetic analysis in the spermatogenesis of Triatoma melanosoma (Reduviidae; Heteroptera). Genet. Mol. Res. 7: 326-335.

Bressa MJ, Papeschi AG, Fumagalli E, van Doesburg PH, et al. (2003). Cytogenetic and nucleolar meiotic cycle analyses in Dysdercus imitator Blote, 1931 (Pyrrhocoridae, Heteroptera) from Argentina. Folia Biol. 51: 135-141.

Bressa MJ, Papeschi AG, Vitkova M, Kubickova S, et al. (2009). Sex chromosome evolution in cotton stainers of the genus Dysdercus (Heteroptera: Pyrrhocoridae). Cytogenet. Genome Res. 125: 292-305.

Castanhole MM, Pereira LL, Souza HV, Bicudo HE, et al. (2008). Heteropicnotic chromatin and nucleolar activity in meiosis and spermiogenesis of Limnogonus aduncus (Heteroptera, Gerridae): a stained nucleolar organizing region that can serve as a model for studying chromosome behavior. Genet. Mol. Res. 7: 1398-1407.

Castanhole MM, Pereira LL, Souza HV and Itoyama MM (2010). Spermatogenesis and karyotypes of three species of water striders (Gerridae, Heteroptera). Genet. Mol. Res. 9: 1343-1356.

Cattani MV and Papeschi AG (2004). Nucleolus organizing regions and semi-persistent nucleolus during meiosis in Spartocera fusca (Thunberg) (Coreidae, Heteroptera). Hereditas 140: 105-111.

Cobben RH (1968). Evolutionary Trends in Heteroptera. Part I. Eggs, Architecture of the Shell, Gross Embryology and Eclosion. Centre for Agricultural Publishing and documentation, Wageningen.

Dundr M, Meier UT, Lewis N, Rekosh D, et al. (1997). A class of nonribosomal nucleolar components is located in chromosome periphery and in nucleolus-derived foci during anaphase and telophase. Chromosoma 105: 407-417. 
Fakan S and Hernandez-Verdun D (1986). The nucleolus and the nucleolar organizer regions. Biol. Cell 56: 189-205. Fischer D, Weisenberger D and Scheer U (1991). Assigning functions to nucleolar structures. Chromosoma 101: 133-140. Fossey A and Liebenberg H (1995). Meiosis and nucleolar structures in the stink bug Carlisis wahlbergi Stal (Coreidae: Heteroptera). Cytobios 81: 7-15.

Gäde G, Auerswald L, Predel R and Marco HG (2004). Substrate usage and its regulation during flight and swimming in the backswimmer, Notonecta glauca. Physiol. Entomol. 29: 84-93.

Gäde G, Auerswald L and Marco HG (2006). Flight fuel and neuropeptidergic control of fuel mobilisation in the twig wilter, Holopterna alata (Hemiptera, Coreidae). J. Insect Physiol. 52: 1171-1181.

Gäde G, Simek P and Marco HG (2007a). A novel adipokinetic peptide in a water boatman (Heteroptera, Corixidae) and its bioanalogue in a saucer bug (Heteroptera, Naucoridae). Peptides 28: 594-601.

Gäde G, Simek P and Marco HG (2007b). Water scorpions (Heteroptera, Nepidae) and giant water bugs (Heteroptera, Belostomatidae): sources of new members of the adipokinetic hormone/red pigment-concentrating hormone family. Peptides 28: 1359-1367.

González-García JM, Rufas JS, Antonio C and Suja JA (1995). Nucleolar cycle and localization of NORs in early embryos of Parascaris univalens. Chromosoma 104: 287-297.

González-García JM, Antonio C, Suja JA and Rufas JS (1996). Meiosis in holocentric chromosomes: kinetic activity is randomly restricted to the chromatid ends of sex univalents in Graphosoma italicum (Heteroptera). Chromosome Res. 4: 124-132.

Grozeva S and Nokkala S (2001). Chromosome numbers, sex determining systems, and patterns of the C-heterochromatin distribution in 13 species of lace bugs (Heteroptera, Tingidae). Folia Biol. 49: 29-41.

Grozeva S, Nokkala S and Simov N (2009). Chiasmate male meiosis in six species of water bugs from infraorders Nepomorpha and Gerromorpha (Insecta: Heteroptera). Comp. Cytogenet. 3: 125-130.

Hofgärtner FJ, Schmid M, Krone W, Zenzes MT, et al. (1979). Pattern of activity of nucleolus organizer during spermatogenesis in mammals as analyzed by silver-staining. Chromosoma197-216.

Howell WM and Black DA (1980). Controlled silver-staining of nucleolus organizer regions with a protective colloidal developer: a 1-step method. Experientia 36: 1014-1015.

John B and King M (1985). Pseudoterminalization, terminalization and non-chiasmate modes of terminal association. Chromosoma 92: 89-99.

Lorenz MW, Kellner R, Temnow K and Woodring J (2009). Identification of the adipokinetic hormone of the large milkweed bug Oncopeltus fasciatus. Physiol. Entomol. 34: 136-143.

Ochs RL, Lischwe MA, Shen E, Carroll RE, et al. (1985). Nucleologenesis: composition and fate of prenucleolar bodies. Chromosoma 92: 330-336.

Papeschi AG and Bressa MJ (2002). Cytogenetic studies in Belostomatidae from Argentina. Abstracts of the Second Quadrennial Meeting of the International Heteropteristis Society, St. Petersburg, 46.

Papeschi AG, Mola LM, Bressa MJ, Greizerstein EJ, et al. (2003). Behaviour of ring bivalents in holokinetic systems: alternative sites of spindle attachment in Pachylis argentinus and Nezara viridula (Heteroptera). Chromosome Res. 11: 725-733.

Rebagliati P, Papeschi AG and Mola LM (2003). Meiosis and fluorescent banding in Edessa meditabunda and E. rufomarginata (Heteroptera: Pentatomidae: Edessinae). Euro. J. Entomol. 100: 11-18.

Rufas JS and Giménez-Martín G (1986). Ultrastructure of the kinetochore in Graphosoma italicum (Hemiptera: Heteroptera). Protoplasma 132: 142-148.

Schwarzacher HG and Wachtler F (1993). The nucleolus. Anat. Embryol. 188: 515-536.

Solari AJ and Agopian S (1987). Recombination nodules, synaptonemal complexes and heterochromatin in the hemipteran Triatoma infestans. Microsc. Electron. Biol. Celular 11: 179-195.

Souza HV, Bicudo HE and Itoyama MM (2007a). Study of chromosomal and nucleolar aspects in testes of Nysius californicus (Heteroptera: Lygaeidae). Genet. Mol. Res. 6: 33-40.

Souza HV, Arakaki RLM, Dias LN, Murakami AS, et al. (2007b). Cytogenetical aspects of testicular cells in economically important species of Coreidae family (Heteroptera). Cytologia 72: 49-56.

Souza HV, Bicudo HEMC, Costa LAA and Itoyama MM (2007c). A study of meiosis and spermatogenesis in different testicular lobes of Antiteuchus tripterus (Heteroptera, Pentatomidae). Euro. J. Entomol. 104: 353-362.

Souza HV, Castanhole MMU, Bicudo HEMC, Costa LAA, et al. (2008). Morphological patterns of the heteropycnotic chromatin and nucleolar material in meiosis and spermiogenesis of Mormidea quinqueluteum, Oebalus poecilus and Oebalus ypsilongriseus (Heteroptera, Pentatomidae). Genet. Mol. Biol. 31: 686-691.

Sumner AT (1990). Chromosome Banding. Unwin Hyman, London.

Takenouchi Y and Muramoto N (1971). A study of the chromosomes in three species of heteropteran insects (Anthocoridae and Veliidae: Heteroptera). J. Hokkaido Univ. Educ. 22: 23-25. 
Tartarotti E and de Azeredo-Oliveira MT (1999). Heterochromatin patterns in triatomines of the genus Panstrongylus. Cytobios 99: 113-122.

Tavares MG and Azeredo-Oliveira MTV (1997). Pattern of nucleolar activity during spermatogenesis in triatomines (Heteroptera: Reduviidae) as analyzed by silver staining. Cytobios 89: 93-103.

Ueshima N (1979). Animal Cytogenetics, Insecta 6, Hemiptera: Heteroptera. Gebruder Borntraeger, Berlin.

Wachtler F and Stahl A (1993). The nucleolus: a structural and functional interpretation. Micron 24: 473-505.

Wolf KW (1996). Acetylation of a-tubulin in male meiotic spindles of Pyrrhocoris apterus, an insect with holocentric chromosomes. Protoplasma 191: 148-157.

Yoshida T (1947). Unusual type of the nucleolus observed in a bug, Acanthocoris sordidus. J. Fac. Sci. Hokkaido Univ. 9: 243-249. 